\title{
Measuring Platelet Reactivity after Clopidogrel - Has it Reached the End of the Road?
}

\section{Cheuk-Kit Wong*}

Associate Professor in Medicine, Department of Cardiology, Dunedin School of Medicine, University of Otago, Dunedin, New Zealand

Clopidogrel is traditionally prescribed at $75 \mathrm{mg}$ daily after a 300 mg loading dose. It is a pro-drug, with a two-step activation process involving a series of cytochrome P-450 (CYP) isoenzymes. Its antiplatelet effect is variable and susceptible to genetic polymorphisms. In particular, patients with either 1 or 2 loss-of-function CYP2C19 alleles have an attenuated pharmacologic response and worse clinical outcomes with standard dose clopidogrel [1]. Among clopidogrel-treated subjects in TRITON-TIMI 38, carriers had higher risk of cardiovascular death, myocardial infarction, or stroke as compared with non-carriers $(12.1 \%$ vs. $8.0 \% ; \mathrm{P}=0.01)$ and higher risk of stent thrombosis $(2.6 \%$ vs. $0.8 \%$; $\mathrm{p}=0.02$ ) [1]. Also, the common polymorphisms in the CYP2C19 gene, seen in approximately $30 \%$ of whites, may be more common in other ethnic groups $-40 \%$ of blacks and $>55 \%$ of East Asians [2]

To achieve higher platelet inhibition, Prasugrel and Ticagrelor are newer $\mathrm{P}_{2} \mathrm{Y}_{12}$ ADP receptor blockers that surpass clopidogrel in platelet inhibition [3,4]. Alternatively increasing clopidogrel dose may sometimes suffice. Among patients with stable cardiovascular disease, tripling the maintenance dose of clopidogrel to $225 \mathrm{mg}$ daily in $C Y P 2 C 19^{*} 2$ heterozygotes, achieved levels of platelet reactivity similar to that seen with the standard $75 \mathrm{mg}$ dose in non-carriers; for CYP2C19*2 homozygotes, doses as high as $300 \mathrm{mg}$ daily did not result in comparable degrees of platelet inhibition [5].

\section{When is Intense P2Y ${ }_{12}$ ADP Receptor Blockade Needed?}

The CURRENT OASIS-7 trial [6,7], undertaken in 597 centres in 39 countries, randomly assigned, in a $2 \times 2$ factorial design, 25086 patients with an acute coronary syndrome who were referred for an invasive strategy to either double-dose clopidogrel (a $600 \mathrm{mg}$ loading dose on day 1 , followed by $150 \mathrm{mg}$ daily for 6 days and $75 \mathrm{mg}$ daily thereafter) or standard-dose clopidogrel (a $300 \mathrm{mg}$ loading dose and $75 \mathrm{mg}$ daily thereafter) and either higher-dose aspirin (300 to $325 \mathrm{mg}$ daily) or lower-dose aspirin (75 to $100 \mathrm{mg}$ daily). Aspirin dose had no effect on outcome.

The primary outcome (cardiovascular death, myocardial infarction, or stroke) at 30 days occurred in $4.2 \%$ of patients assigned to doubledose clopidogrel as compared with $4.4 \%$ assigned to standard-dose clopidogrel ( $\mathrm{p}=0.30$ ). Major bleeding occurred in $2.5 \%$ of patients in the double-dose group and in $2.0 \%$ in the standard-dose group $(\mathrm{p}=0.01)$. In the 17,263 individuals who underwent PCI, double-dose clopidogrel reduced the rate of the primary outcome $(3.9 \%$ vs. $4.5 \% ; \mathrm{p}=0.039)$ and definite stent thrombosis $(0.7 \%$ vs. $1.3 \% ; \mathrm{p}=0.0001)$, when compared to the standard dose.

These findings illustrate that clopidogrel dosage and consequently the degree of platelet inhibition only matters in patients undergoing stenting but not in those managed medically. This conclusion echoes well with the recent findings from the TRILOGY ACS study [8] and its platelet function sub study [9] showing that both the use of prasugrel and the consequent stronger platelet inhibition as measured by the point-of care Verify Now P2Y ${ }_{12}$ testing (Accumetrics, San Diego,
California) have no independent relationship to outcome compared to the use of standard dose clopidogrel, in a cohort of medically managed patients.

\section{Can Measuring ADP Mediated Platelet Reactivity after Clopidogrel Guide Therapy in Patients Undergoing Stenting/PCI?}

A collaborative meta-analysis [10] used patient-level data for the Verify Now P2 $\mathrm{Y}_{12}$ assay to assess clopidogrel responsiveness in 3,059 patients after PCI. The primary endpoint of composite death, myocardial infarction, or stent thrombosis occurred more frequently in higher quartiles of $\mathrm{P}_{2} \mathrm{Y}_{12}$ reaction unit (PRU) values: quartile I, 5.8\%; quartile II, 6.9\%; quartile III, 10.9\%; quartile IV, $15.8 \%(\mathrm{p}<0.001)$. According to ROC curve analysis, a PRU value of 230 appeared to best predict outcome $(\mathrm{p}<0.001)$. A PRU value $\geq 230$ was associated with a higher rate of the individual endpoints of death (HR: 1.66; 95\% CI: 1.04 to $2.68 ; \mathrm{p}=0.04$ ), myocardial infarction (HR: $2.04 ; 95 \% \mathrm{CI}: 1.51$ to $2.76 ; \mathrm{p}<0.001$ ), and stent thrombosis (HR: $3.11 ; 95 \% \mathrm{CI}: 1.50$ to 6.46 ; $\mathrm{p}=0.002)$.

Mechanistically, stent thrombosis is a particularly relevant outcome as imaging studies months to year's post-stenting have clearly documented areas of stent malapposition, ectasia, neoatherosclerosis with thin cap atheroma and even thrombus formation [11]. How these pathological changes mediate the sequence of events leading to stent thrombosis remain to be fully explored.

Several studies tested whether identifying patients with high on-treatment platelet reactivity (based on a PRU cut-off value) and potentiating anti-platelet regime will improve outcome. The 2214-patient GRAVITAS trial [12] showed that increasing the clopidogrel maintenance dose from $75 \mathrm{mg}$ to $150 \mathrm{mg}$ daily early after PCI did not lower ischemic events, but the cohort was consisting of low-risk subjects with event rate of only $2.3 \%$ at 6 months in both randomised groups (stent thrombosis $0.5 \%$ with high dose and $0.7 \%$ with standard dose clopidogrel, $\mathrm{p}=0.42$ ). The TRIGGER-PCI trial [13] was also prematurely terminated because of a lower than expected event rate, randomising only 423 patients.

In the most recent French ARTIC study [14], 2440 patients

*Corresponding author: Cheuk-Kit Wong, Associate Professor in Medicine Department of Cardiology, Dunedin School of Medicine, University of Otago, Dunedin, New Zealand, Tel: 643-4747980; Fax: 643-4747655; E-mail: cheuk-kit.wong@healthotago.co.nz

Received November 20, 2012; Accepted November 21, 2012; Published November 23, 2012

Citation: Wong CK (2013) Measuring Platelet Reactivity after Clopidogrel Has it Reached the End of the Road? Cardiol Pharmacol 2:e105 doi:10.4172/2329-6607.1000e105

Copyright: () 2013 Wong CK. This is an open-access article distributed under the terms of the Creative Commons Attribution License, which permits unrestricted use, distribution, and reproduction in any medium, provided the original author and source are credited. 
Citation: Wong CK (2013) Measuring Platelet Reactivity after Clopidogrel - Has it Reached the End of the Road? Cardiol Pharmacol 1:e105. doi:10.4172/2329-6607.1000e105

scheduled for coronary stenting were randomised to a strategy of platelet-function monitoring with drug adjustment in patients who had a poor response to antiplatelet therapy, or to a conventional strategy without monitoring and drug adjustment. The primary end point was the composite of death, myocardial infarction, stent thrombosis, stroke, or urgent revascularization 1 year after stent implantation. For patients in the monitoring group, the Verify Now P2 $\mathrm{Y}_{12}$ and aspirin point-of-care assays were used in the catheterization laboratory before stent implantation and in the outpatient clinic 2 to 4 weeks later.

In the monitoring group, high platelet reactivity in patients taking clopidogrel (34.5\% of patients) or aspirin (7.6\%) led to the administration of an additional bolus of clopidogrel, prasugrel, or aspirin along with glycoprotein IIb/IIIa inhibitors during the procedure. The primary end point occurred in $34.6 \%$ of the patients in the monitoring group, as compared with $31.1 \%$ of those in the conventional-treatment group (HR 1.13; 95\% CI 0.98 to $1.29 ; \mathrm{p}=0.10$ ). The main secondary end point, stent thrombosis or any urgent revascularization, occurred in $4.9 \%$ of the patients in the monitoring group and $4.6 \%$ of those in the conventional-treatment group (HR 1.06; 95\% CI, 0.74 to $1.52 ; \mathrm{P}=0.77$ ). Stent thrombosis rate was $1.0 \%$ vs. $0.7 \%$ respectively $(\mathrm{p}=0.51)$. The rate of major bleeding events did not differ significantly between groups.

In summary, no studies has shown any significant improvements in clinical outcomes with platelet-function monitoring and treatment adjustment for PCI and coronary stenting, as compared with standard antiplatelet therapy without monitoring.

\section{Measuring ADP-Mediated Platelet Reactivity after Clopidogrel - Has it Reached the End of the Road?}

Before condemning the currently easily available platelet function test, the possibility exists that investigators might not have studied the real high-risk patients - those with coronary thrombotic lesions, challenging anatomy that requires extensive multiple stenting, bifurcation reconstructions, anatomy that is unlikely to give satisfactory PCI results, or systematically higher thrombotic risk patients including those with renal failure. The event rate in ARTIC was mainly driven by peri-procedural myocardial infarction. Stent thrombosis rate was low both in GRAVITAS [12] and ARTIC [14]. In contrast the SYNTAX trial involving multi-vessel stenting and more complex interventions reported a much higher 1-year adjudicated stent thrombosis rate at $3.3 \%$ using the TAXUS stent [15].

Modern stent technology has continued to improve the efficacy and safety of PCI and the cobalt-chromium everolimus eluting stents has the lowest rate of stent thrombosis within 2 years of implantation, compared to other drug-eluting stents and bare metal stents [16]. The field is definitely fast evolving but clopidogrel will continue to be widely used given its much lower cost than newer, more potent antiplatelet agents. Intuitively there should always be useful information from bedside platelet function testing in patients presenting with stent thrombosis or severe bleeding, when tailored antiplatelet therapy may best match the clinical situation.

\section{References}

1. Mega JL, Close SL, Wiviott SD, Shen L, Hockett RD, et al. (2009) Cytochrome P-450 polymorphisms and response to clopidogrel. N Engl J Med 360: 354-362.

2. Desta Z, Zhao X, Shin JG, Flockhart DA (2002) Clinical significance of the cytochrome P450 2C19 genetic polymorphism. Clin Pharmacokinet 41: 913958.

3. Wiviott SD, Trenk D, Frelinger AL, O'Donoghue M, Neumann FJ, et al. (2007) Prasugrel compared with high loading- and maintenance-dose clopidogrel in patients with planned percutaneous coronary intervention: the Prasugrel in
Comparison to Clopidogrel for Inhibition of Platelet Activation and AggregationThrombolysis in Myocardial Infarction 44 trial. Circulation 116: 2923-2932.

4. Bliden KP, Tantry US, Storey RF, Jeong YH, Gesheff M, et al. (2011) The effect of ticagrelor versus clopidogrel on high on-treatment platelet reactivity: combined analysis of the ONSET/OFFSET and RESPOND studies. Am Heart J 162: 160-165.

5. Mega JL, Hochholzer W, Frelinger AL 3rd, Kluk MJ, Angiolillo DJ, et al. (2011) Dosing Clopidogrel Based on CYP2C19 Genotype and the Effect on Platelet Reactivity in Patients With Stable Cardiovascular Disease. JAMA 306: 2221-2228.

6. CURRENT-OASIS 7 Investigators, Mehta SR, Bassand JP, Chrolavicius S Diaz R, et al. (2010) Dose Comparisons of Clopidogrel and Aspirin in Acute Coronary Syndromes. N Engl J Med 363: 930-942.

7. Mehta SR, Tanguay JF, Eikelboom JW, Jolly SS, Joyner CD, et al. (2010) Double-dose versus standard-dose clopidogrel and high-dose versus low-dose aspirin in individuals undergoing percutaneous coronary intervention for acute coronary syndromes (CURRENT-OASIS 7): a randomised factorial trial. Lancet 376: 1233-1243

8. Roe MT, Armstrong PW, Fox KA, White HD, Prabhakaran D, et al. (2012) Prasugrel versus clopidogrel for acute coronary syndromes without revascularization. N Engl J Med 367: 1297-1309.

9. Gurbel PA, Erlinge D, Ohman EM, Neely B, Neely M, et al. (2012) Platelet function during extended prasugrel and clopidogrel therapy for patients with ACS treated without revascularization: the TRILOGY ACS Platelet Function Substudy. JAMA 308: 1785-1794.

10. Brar SS, Ten Berg J, Marcucci R, Price MJ, Valgimigli M, et al. (2011) Impact of platelet reactivity on clinical outcomes after percutaneous coronary intervention. a collaborative meta-analysis of individual participant data. J Am Coll Cardiol 58: $1945-1954$

11. Kim JS, Hong MK, Shin DH, Kim BK, Ko YG, et al. (2012) Quantitative and Qualitative Changes in DES-Related Neointimal Tissue Based on Serial OCT. JACC Cardiovasc Imaging 5: 1147-1155.

12. Price MJ, Berger PB, Teirstein PS, Tanguay JF, Angiolillo DJ, et al. (2011) Standard- vs high-dose clopidogrel based on platelet function testing after percutaneous coronary intervention: the GRAVITAS randomized trial. JAMA 305: 1097-1105.

13. Trenk D, Stone GW, Gawaz M, Kastrati A, Angiolillo DJ, et al. (2012) A randomized trial of prasugrel versus clopidogrel in patients with high platelet reactivity on clopidogrel after elective percutaneous coronary intervention with implantation of drug-eluting stents: results of the TRIGGER$\mathrm{PCl}$ (Testing Platelet Reactivity In Patients Undergoing Elective Stent Placement on Clopidogrel to Guide Alternative Therapy With Prasugrel) study. J Am Coll Cardiol 59: 2159-2164.

14. Collet JP, Cuisset T, Range G, Cayla G, Elhadad S, et al. (2012) Bedside monitoring to adjust antiplatelet therapy for coronary stenting. $\mathrm{N}$ Engl J Med 367: 2100-2109.

15. Serruys PW, Morice MC, Kappetein AP, Colombo A, Holmes DR, et al. (2009) Percutaneous Coronary Intervention versus Coronary-Artery Bypass Grafting for Severe Coronary Artery Disease. N Engl J Med 360: 961-972.

16. Palmerini T, Biondi-Zoccai G, Della Riva D, Stettler C, Sangiorgi D, et al. (2012) Stent thrombosis with drug-eluting and bare-metal stents: evidence from a comprehensive network meta-analysis. Lancet 379: 1393-1402. 